\title{
Small intestinal mucosal fat in childhood enteropathies
}

\author{
S VARIEND, * MONICA PLACZEK,$\dagger$ F RAAFAT, $\ddagger$ JA WALKER-SMITH $\dagger$
}

From the $\dagger$ Academic Department of Child Health and $\ddagger$ Department of Pathology, Queen Elizabeth Hospital for Children, London, the *Department of Pathology, Children's Hospital, Sheffield

SUMMARY A sequential series of 100 small bowel mucosal biopsies from children was studied to assess the frequency and pattern of mucosal fat staining, and to compare patterns of fat distribution with mucosal structure and clinical diagnosis. Deep mucosal fat was commonly associated with those clinical groups showing normal mucosal structure. While fine granular surface epithelial fat was common in normal and abnormal biopsies, the presence of large fat globules in the surface epithelium was almost entirely limited to biopsies showing villous shortening. Large fat globules in the surface epithelium in coeliac disease and cow's milk sensitive enteropathy were probably related to the more severe degrees of villous abnormality encountered in these clinical groups. However, large fat globules in surface epithelium were also found in a few cases of cow's milk sensitive enteropathy with normal or minimal villous blunting. Fat staining may be a useful additional histological marker to aid in the interpretation of small intestinal mucosal biopsies.

Recent developments in paediatric gastroenterology have been attended by an increase in the recognition of a number of small intestinal lesions characterised by a histologically abnormal small intestinal mucosa. Successful management is based on an accurate diagnosis, which is most profitably resolved by a combined approach utilising clinical, laboratory and morphological data, as well as a response to dietary manipulation.

Histological assessment may be difficult when villous architecture is only mildly or equivocally altered, a problem compounded in children where age may influence appearance. Thus, new techniques which aid histological interpretation should be encouraged.

While the few previous reports concerning fat in small intestinal mucosa have been of a physiological nature and have only dealt with normal mucosa, apart from abetalipoproteinaemia, mucosal fat in small intestinal disease has not been previously investigated. The purpose of this investigation was to assess the frequency, appearance and location of fat in small bowel mucosa and to compare this with mucosal structure and final clinical diagnosis.

\section{Material and methods}

Biopsies were obtained from the fourth part of the Accepted for publication 30 November 1983 duodenum using a double port paediatric Crosby capsule $^{1}$ under $x$ ray control. All patients were starved for a minimum period of $10 \mathrm{~h}$ prior to biopsy. The two specimens obtained from each patient were first examined under a dissecting microscope and photographed. Tissue from specimen 1 was used for the measurement of disaccharidases using a modification of the method of Dalquist. ${ }^{2}$ Cryostat sections were cut from the first specimen and stained for fat using the Sharlach $\mathrm{R}$ method; the tissue was then embedded in Ester wax. Specimen 2 was embedded directly in Ester wax. Sections $(6 \mu \mathrm{m})$ were cut from both specimens, stained with haematoxylin and eosin and examined by light microscopy.

Mucosal morphology was assessed as normal or, depending on the degree of abnormality, mild patchy $(\mathrm{N} /+)$, mild $(+)$, moderate $(++)$ or severe $(+++){ }^{3}$ When the two specimens showed different degrees of villous blunting, for the purpose of this classification, only the most severe degree was considered. The term "patchy" was used when one of the specimens was structurally normal and the other showed some degree of abnormality. ${ }^{4}$

One hundred sequential biopsies from 96 patients were studied; ages ranged from two months to $15 \mathrm{yr}$. Clinical indications for biopsy included chronic diarrhoea, failure to thrive, and short stature.

Thirty three of these cases served as controls. 
These were from (i) 19 cases in which the biopsies showed normal villous architecture and normal disaccharidase activity, thus excluding a small intestinal cause for the symptoms; (ii) four cases with chronic diarrhoea which resolved following investigations and demonstration of normal small intestinal mucosa; (iii) 10 cases of healed or near-healed mucosa in "pre-challenge" biopsies prior to successful milk or gluten challenge.

In addition to the controls, there were seven diagnostic groups (see Table 1). Coeliac disease was diagnosed in children presenting with appropriate clinical symptoms in whom the biopsy showed moderate to severe enteropathy associated with significant cellular infiltration of the surface epithelium and lamina propria, and who responded clinically to gluten withdrawal. There has not yet been time to fulfil the Interlaken criteria. ${ }^{5}$

Cow's milk sensitive enteropathy was most commonly a sequel to acute gastroenteritis and presented as failure to thrive with or without diarrhoea and vomiting. The biopsy showed mild to moderate villous atrophy of patchy distribution but significant cellular infiltration of the surface epithelium was rare. There was always clinical improvement on cows' milk withdrawal. Postenteritis enteropathy had a similar clinical presentation and histological picture, but elimination of cows' milk protein was either unnecessary or unhelpful.

Toddler's diarrhoea ${ }^{6}$ presented with diarrhoea as the sole clinical symptom and the small intestinal villous structure was always normal. Children with multiple food intolerance were frequently atopic and a family history of atopy was common. Raised serum $\operatorname{IgE}$ and eosinophilia were frequent and the radioallergosorbent tests for specific foodstuffs such as milk, fish and eggs were usually positive.

Lactase deficiency, frequently in combination with depression of other disaccharidases, was common in coeliac disease, cow's milk sensitive enteropathy and postenteritis enteropathy. However, when it occurred as an isolated feature in

Table 1 Diagnostic groups

\begin{tabular}{lccc}
\hline & $\begin{array}{c}\text { No of } \\
\text { cases }\end{array}$ & Age range & $\begin{array}{c}\text { Mean } \\
(y r)\end{array}$ \\
\hline Controls & 33 & $5 \mathrm{~m}-13 \mathrm{yr}$ & $4 \cdot 1$ \\
Coeliac disease & 9 & $1 \mathrm{yr}-9 \mathrm{yr}$ & $4 \cdot 4$ \\
CMSE & 21 & $2 \mathrm{~m}-2 \mathrm{yr}$ & $0 \cdot 5$ \\
Postenteritis & 8 & $7 \mathrm{~m}-2 \mathrm{yr}$ & $1 \cdot 0$ \\
Toddler's diarrhoea & 8 & $1 \mathrm{yr}-4 \mathrm{yr}$ & $1 \cdot 9$ \\
MFI & 10 & $3 \mathrm{~m}-15 \mathrm{yr}$ & $2 \cdot 8$ \\
Lactase deficiency & 6 & $3 \mathrm{~m}-13 \mathrm{yr}$ & $6 \cdot 5$ \\
Miscellaneous & 5 & $5 \mathrm{~m}-10 \mathrm{yr}$ & 3.8 \\
\hline
\end{tabular}

CMSE = cows' milk sensitive enteropathy.

MFI = multiple food intolerance.
Table 2 Villous structure in different diagnostic groups

\begin{tabular}{llllll}
\hline & $N$ & $N /+$ & + & ++ & +++ \\
\hline Controls & 33 & - & - & - & - \\
Coeliac disease & - & - & - & 2 & 7 \\
CMSE & 2 & 3 & 7 & 9 & - \\
Postenteritis & 3 & 1 & 1 & 2 & 1 \\
Toddler's diarrhoea & 8 & - & - & - & - \\
MFI & 4 & 4 & 2 & - & - \\
Lactase deficiency & 6 & - & - & - & - \\
Miscellaneous & 3 & 1 & 1 & - & - \\
\hline
\end{tabular}

CMSE = cows' milk sensitive enteropathy.

MFI = multiple food intolerance.

association with a normal mucosa, the case was assigned to a specific lactase deficiency group. A miscellaneous group comprised two cases of giardiasis, one case of cystic fibrosis, one case of intestinal obstruction (probably secondary to intestinal malrotation) and one case of sucrase-isomaltase deficiency. Table 2 shows the villous structure in relation to clinical diagnosis.

\section{Results}

Sharlach $\mathrm{R}$ staining of the small intestinal mucosal biopsies showed four easily definable patterns:

(A) No significant fat

(B) Positive speckling in lamina propria

(C) Fat in the deep lamina propria

(D) Fat in the surface epithelium

Fat in the surface epithelium was further divided into two groups - (i) fine granules, and (ii) large globules.

Eighteen biopsies showed no significant fat staining (A) while positive focal speckling in the connective tissue of the lamina propria (B) was seen in twelve biopsies. These two patterns did not correlate with any particular clinical group, degree of villous abnormality, disaccharidase deficiency, or the diet at the time of biopsy.

Of the remaining 70 biopsies, 46 showed fat staining in the deep lamina propria (C) (Fig. 1) and 41 showed fat in the surface epithelium (D). Thus, 17 biopsies showed simultaneous deep mucosal fat and surface epithelial fat.

Deep mucosal fat occurred frequently in the controls $(66 \%)$, postenteritis $(50 \%)$, multiple food intolerance $(70 \%)$, lactase deficiency $(66 \%)$ and the miscellaneous group (80\%) and was comparatively less frequent in cow's milk sensitive enteropathy and toddler's diarrhoea (Table 3). It was not, however, seen in cases of coeliac disease.

When surface epithelial fat, classified according to size of fat particles, was assessed there were 28 cases with fine granules (Fig 2(a) and (b)) and 13 with 
Table 3 Patterns of fat staining related to clinical diagnosis

\begin{tabular}{lcccc}
\hline & No of cases & $\begin{array}{l}\text { Deep mucosal } \\
\text { fat }\end{array}$ & $\begin{array}{l}\text { Surface epithelial } \\
\text { fat (fne granules) }\end{array}$ & $\begin{array}{l}\text { Surface epithelial } \\
\text { fat (large globules) }\end{array}$ \\
\hline Controls & 33 & $22(66)$ & $7(21)$ & $0-5-$ \\
Coeliac disease & 9 & $0-$ & $2(22)$ & $7(55)$ \\
CMSE & 21 & $4(19)$ & $3(14)$ & $0-$ \\
Postenteritis & 8 & $4(50)$ & $4(50)$ & $0-$ \\
Toddler's diarrhoea & 8 & $1(12)$ & $2(25)$ & $0-$ \\
MFI & 10 & $7(70)$ & $4(40)$ & $1(16)$ \\
Lactase deficiency & 6 & $4(66)$ & $4(66)$ & $0-$ \\
Miscellaneous & 5 & $4(80)$ & $2(40)$ & \\
\hline
\end{tabular}

CMSE = cows' milk sensitive enteropathy.

MFI = multiple food intolerance

Percentages are shown in parentheses.
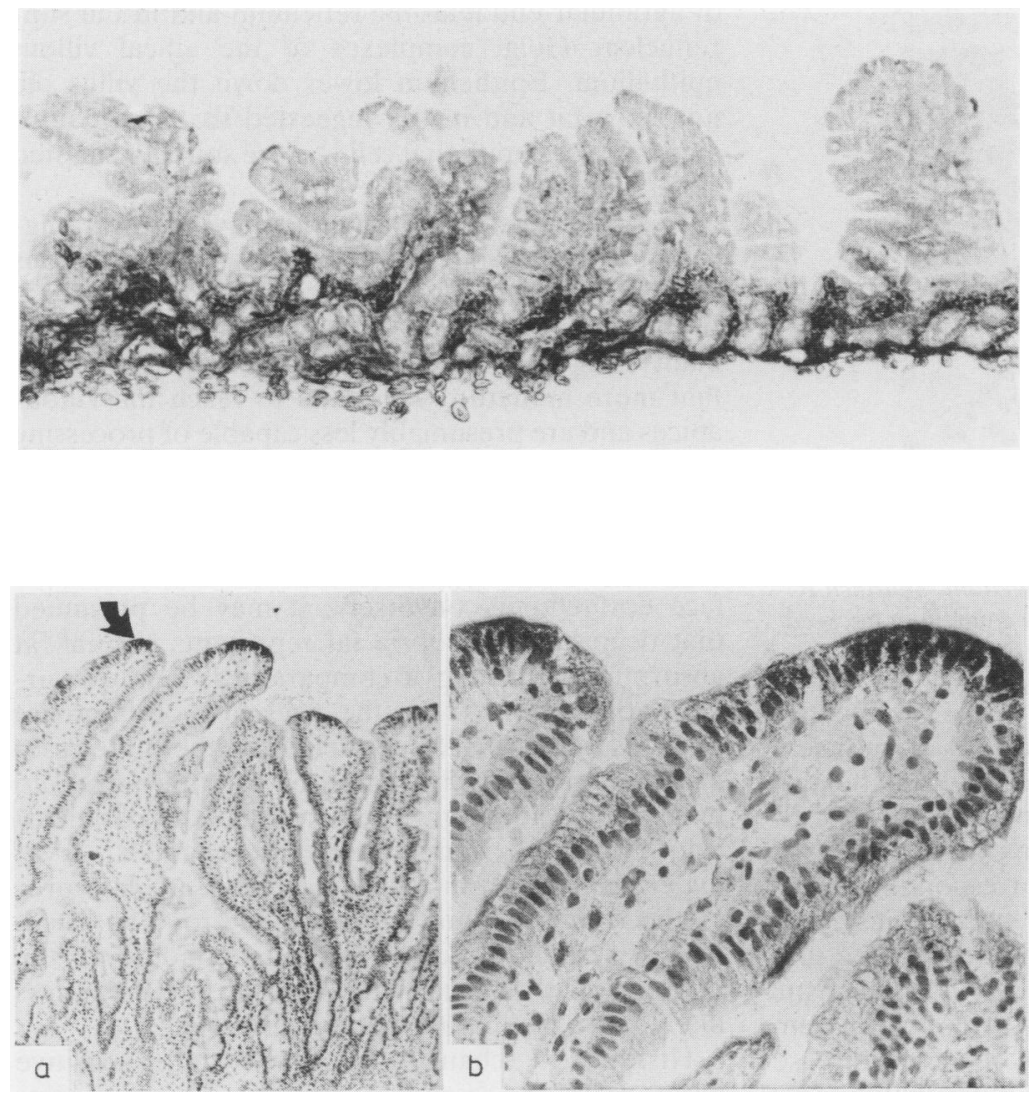

Fig. 1 Normal small bowel mucosa showing fat concentrated in the basal lamina propria. Sharlach $R \times 50$.

Table 4 Pattern of fat staining related to villous morphology

\begin{tabular}{llll}
\hline $\begin{array}{l}\text { Villous structure } \\
()=\text { no of cases }\end{array}$ & $\begin{array}{l}\text { Deep mucosal fat } \\
()=\%\end{array}$ & $\begin{array}{l}\text { Small particles in } \\
\text { surface epithelium } \\
()=\%\end{array}$ & $\begin{array}{l}\text { Large globules in } \\
\text { surface epithelium } \\
()=\%\end{array}$ \\
\hline $\mathrm{N}(59)$ & $34(55)$ & $18(30)$ & $2(3)$ \\
$\mathrm{N} /+(9)$ & $3(33)$ & $2(22)$ & $0-(18)$ \\
$+(11)$ & $5(45)$ & $2(18)$ & $2(30)$ \\
$++(13)$ & $4(30)$ & $2(25)$ & $5(62)$ \\
$+++(8)$ & $0-$ & $2(25)$ & \\
\hline
\end{tabular}

Fig. 2 (a) Fine fat particles are present in the surface epithelium (arrow). The villous pattern is normal. Sharlach $R \times 58$. (b) Fine fat particles in surface epithelium are seen under high magnification. Sharlach $R \times 228$. 


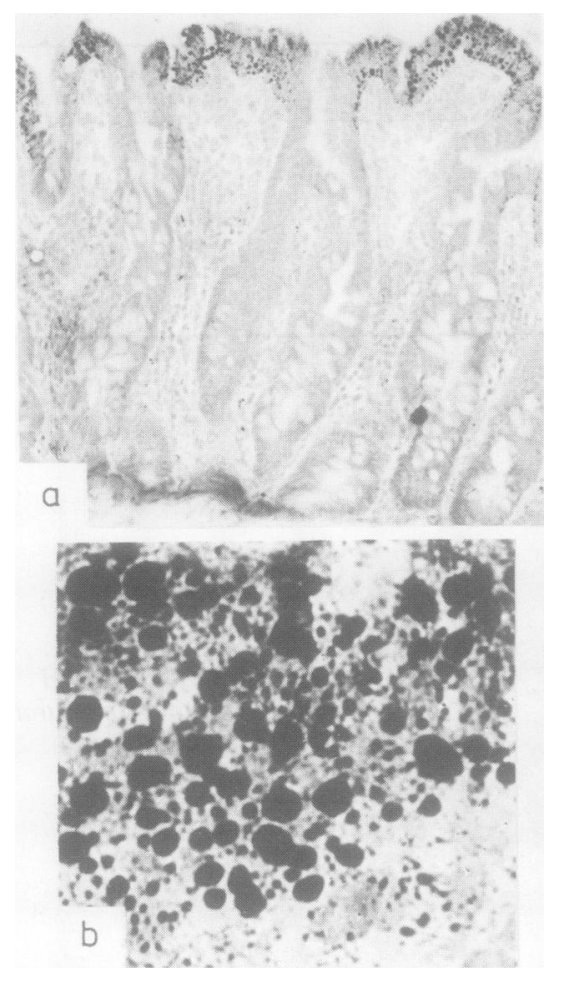

Fig. 3 (a) Small bowel mucosa with moderate villous blunting due to cows' milk sensitive enteropathy. Large fat globules are present in the surface epithelium. Sharlach $R$ $\times 90$. (b) Large globules in the surface epithelium are seen under high magnification. Sharlach $R \times 530$.

large globules (Fig. 3(a) and (b)). The discrepancy in size of the fat particles was always of sufficient degree to allow easy distinction between the two groups. Epithelium with fine granules characteristically showed a focal paranuclear concentration on the luminal aspect, presumably corresponding to the Golgi complex. Comparison between type of surface epithelial fat and the clinical diagnoses showed that fine granules were common in all the diagnostic groups while large globules in the surface epithelium were virtually limited to five cases of coeliac disease and seven of cow's milk sensitive enteropathy. Two cases of cow's milk sensitive enteropathy with large globules showed only mild villous blunting and one showed a normal villous pattern. This contrasted with five cases of coeliac disease with large fat globules in the surface epithelium. One other case showing large globules in the surface epithelium associated with a normal villous pattern was a child with failure to thrive and constipation. Mucosal lactase was decreased and the clinical problem remains unresolved.
Mucosal structure in relation to deep mucosal fat and types of surface epithelial fat is shown in Table 4. Deep mucosal fat was most commonly associated with a normal villous pattern $(55 \%)$ and was less frequently associated with biopsies showing villous shortening. There was no instance of deep mucosal fat when the villous abnormality was severe in degree.

\section{Discussion}

Ultrastructural studies in animals ${ }^{78}$ and $\operatorname{man}^{9}$ have shown that surface epithelial fat is present following a fatty meal and that the fat is usually within profiles of agranular endoplasmic reticulum and in the supranuclear Golgi complexes of the apical villous epithelium. Epithelium lower down the villus did not show fat and it was suggested that the mature apical surface epithelial cell is more suitably adapted to fat absorption.

The mechanism of continuous physiological migration of cells from the crypt bases to the villous apices to replace effete enterocytes is recognised. ${ }^{10}$ In those disorders with a structural mucosal abnormality, this process is known to be accelerated so that more immature cells tend to reach the villous apices and are presumably less capable of processing dietary fat.

The relationship between large globules in the surface epithelium and abnormal mucosal structure suggests that fat accumulates in the immature surface epithelium; conversely, it may be presumed that deep lamina propria fat represents normal fat absorption reflecting a comparatively mature surface epithelium. Thus, the presence of large fat globules in the surface epithelium of the three cases of cow's milk sensitive enteropathy with normal to mild villous blunting was unexpected and paradoxical. Compared with other enteropathies, crypt hypertrophy and mucosal thickening are less pronounced in cow's milk sensitive enteropathy ${ }^{11}$ and, with a greater cell turnover in that condition, ${ }^{12}$ the maturity of the apical villous surface epithelium is likely to be comparatively less advanced.

Histological changes in cow's milk sensitive enteropathy are essentially non-specific and a combined clinico-pathological approach is usually required for final diagnosis. The small number of cases in this study does not warrant any firm conclusion but the diffuse large globules in the surface epithelium in one third of the cases of cow's milk sensitive enteropathy may prove a useful histological marker of that diagnosis. The mucosal abnormality in cow's milk sensitive enteropathy and postenteritis enteropathy are not ordinarily distinguishable histologically. The presence of large fat 
globules in the surface epithelium in $33 \%$ of cases of cow's milk sensitive enteropathy and their absence in the cases of post enteritis enteropathy is noteworthy and may prove useful in their differentiation. Significant degrees of fat in the surface epithelium probably represent a morphological basis of steatorrhoea that frequently accompanies the enteropathic disorders.

Significant fat accumulation in the surface epithelium of the small intestine is conventionally associated with abetalipoproteinaemia. ${ }^{13} \mathrm{~A}$ vacuolated, bloated, apical surface epithelium and a normal villous structure are the histological hallmarks of this condition which, with the associated clinical symptoms, should allow easy distinction from the marked fat staining reported here.

We thank Mr AD Phillips for valuable advice and Mrs BP Wilson for typing the manuscript.

\section{References}

1 Kilby A. Paediatric small intestinal biopsy capsule with two ports. Gut 1976;17:158-9.

${ }^{2}$ Phillips AD, Avigod S, Sacks J, Rice SJ, France NE, WalkerSmith JA. Microvillous surface area in secondary disaccharidase deficiency. Gut 1980;21:44-8.

${ }^{3}$ Harrison M, Kilby A, Walker-Smith JA. Cows' milk protein into- lerance: A possible association with gastroenteritis, lactose intolerance, and IgA deficiency. Br Med J 1976;i:1501-4.

4 Manuel PD, Walker-Smith JA, France NE. Patchy enteropathy in childhood. Gut 1979;20:211.

${ }^{5}$ Meeuwisse GW. Diagnostic criteria in coeliac disease. Acta Paediatr Scand 1970;59:461-3.

- Walker-Smith JA. Toddler's diarrhoea. Arch Dis Childh 1980;55:329.

' Palay SL, Karlin LJ. An electron microscopic study of the intestinal villus. II. The pathway of fat absorption. Biophys Biochem Cytol 1959;5:373-83.

${ }^{8}$ Ashworth CT, Johnston JM. The intestinal absorption of fatty acid: A biochemical and elctron microscopic study. J Lip Res 1963;4:454-60.

' Ladman AJ, Padykula HA, Strauss EW. A morphological study of fat transport in the normal human jejunum. Am J Anat 1963; 112:389-425.

${ }^{10}$ Booth CC. Enterocyte in coeliac disease. $\mathrm{Br}$ Med $\mathrm{J}$ 1970;iii:725-31.

"Maluenda C, Phillips AD, Briddon A, Walker-Smith JA. Quantitative analysis of small intestinal mucosa in cows' milk sensitive enteropathy. J Ped Gastroenterol Nutr (in press)

${ }^{12}$ Kosnai I, Kuitunen P, Savilakti E, Rapola J, Kohegyi J. Cell kinetics in the jejunal crypt epithelium in malabsorption syndrome with cows' milk protein intolerance and coeliac disease of childhood. Gut 1980;21:1041-6.

${ }^{13}$ Lamy M, Frezal J, Polonovski J, Druez G, Rey J. Congenital absence of beta-lipoprotein. Pediatrics 1963;32:277-89.

Requests for reprints to: Dr S Variend, Department of Pathology, Children's Hospital, Western Bank, Sheffield, S10 2TH, England. 